\title{
The Digital Divide Across All Citizens of the World: A New Concept
}

\author{
Jeffrey James
}

Accepted: 4 June 2007/Published online: 7 July 2007

(C) Springer Science+Business Media B.V. 2007

\begin{abstract}
This paper is concerned with the requirements for and implications of, moving from the confines of the conventional concept of the digital divide to one that reflects a world distribution of Internet users with different income levels, with particular reference to those users living in poverty. The first part of the note provides a simple, sequential, two-country illustration of what such a transition would entail. The resulting framework is then used to revisit the much-discussed issue of recent changes in Internet use between rich and poor countries. One mechanism that is associated with the revised concept is shown to substantially reduce the size of the digital divide as conventionally measured. The other mechanism, by contrast, works in the opposite direction because the increased number of users in developing countries are drawn from high-income, educated and urban classes, creating a highly unequal distribution within these countries.
\end{abstract}

Keywords Global distribution · Internet use · Digital divide $\cdot$ Poverty

\section{Introduction}

This paper advances the novel point of view that the digital divide needs to be conceptualized and measured not only between unweighted averages of rich and poor countries but also in terms of all global citizens, regardless of where they live. For this purpose there is a need to know not only the income levels of those who use the Internet, but also whether and to what extent they can be described as living in poverty (as measured for instance by 1 dollar per day). After all, much of the literature on information technology and development is concerned to emphasize the positive influence of this technology on poverty and the Millennium Development Goals more generally. Recently, for example, UNCTAD

J. James ( $($ )

Department of Economics, Tilburg University, Warandelaan 2, Tilburg 5000 LE, The Netherlands

e-mail: m.j.james@uvt.nl 
(2006) argued that 'Information and communication technologies (ICTs) have opened up new opportunities to alleviate poverty and have changed the way in which poverty reduction efforts take place' (p. 169). In the same year, an ITU (International Telecommunications Union) report refers to the World Summit on the Information Society meeting held in Tunis, which highlights the potential of ICTs in 'improving the socio-economic development of all human beings' and points to the 'growing importance of the role of ICTs... as a tool for the achievement for the internationally-agreed development goals and objectives, including the Millennium Development Goals' (ITU 2006, p. 3).

Yet, in reality, the conventional concept of the digital divide-as the gap in ICT use between rich and poor countries-provides us with little or no information on the divide between the citizens of the world, who are differentiated on the basis of income levels, information which would allow us to assess Internet use and welfare among the poorest members of global society. It would also allow us to trace changes in the degree of world inequality in Internet use, among individuals with different income levels. In the sections below, I seek, accordingly, to describe the various mechanisms through which the original concept of the digital divide can be transformed into the new idea that has just been described. I illustrate this transition by means of a simple two-country, two-persons per country framework using actual numerical examples. I then indicate, with reference to the growth of Internet use in recent years, how the mechanisms thus identified have contributed to inequality across all Internet users in the world, rich and poor alike. The discussion in this section alludes to and draws upon a closely parallel debate that exists in the literature on the change in the so-called global distribution of income. ${ }^{1}$ It also makes an initial attempt to calculate part of the information that will determine the extent of inequality in use for the world as a whole. I conclude by drawing out the directions for future research and data collection that a reconceptualized digital divide would entail.

\subsection{Reconceptualizing the Digital Divide}

Whereas the digital divide is conventionally about differences between (rich and poor) countries, a reconceptualized version would be about individuals and their differences. Following the entries in Table 1, I show that the transformation from the one concept to the other involves two steps. The first is to provide a more accurate map of world Internet use by weighting the number of users per country by the population of that country. Since even this more accurate map provides no information about Internet use within each country a further step is needed to arrive at an array of global users, ranked by their income levels, regardless of where they live. Using arbitrarily chosen numbers, let us now use Table 1 to illustrate the transition from the one concept to the other.

The table begins with an illustration of the digital divide as it is conventionally measured. The rich country has a per capita income of $\$ 200$ and the poor country has only half that amount (it is implicitly assumed in this measure that each person in each country has the income corresponding to the country average). Because there are twice the number of Internet users (per 100 persons) in the rich rather than the poor country, the divide is simply 2 to 1 . Rather than assuming that the population size is the same in each country, however, I allow for differences between the two (in particular, I assume, purely for the sake of argument that the rich country has a population of 10 persons, half that of the poor

\footnotetext{
${ }^{1}$ See the list of references contained in Sala-I-Martin (2002), for example.
} 
Table 1 From the original to the new concept of the digital divide

\begin{tabular}{|c|c|c|}
\hline & Developed country & Developing country \\
\hline \multicolumn{3}{|l|}{ The original divide } \\
\hline Per capita income & $\begin{array}{l}\$ 200 \text { (where each member of } \\
\text { society has the same per } \\
\text { capita income) }\end{array}$ & $\begin{array}{l}\$ 100 \text { (where each member of society } \\
\text { has the same per capita income) }\end{array}$ \\
\hline Internet users (per 100 persons) & 20 & 10 \\
\hline Size of divide $(2: 1)$ & 2 & 1 \\
\hline \multicolumn{3}{|l|}{ Weighting the original divide } \\
\hline Population size & 10 persons & 20 persons \\
\hline Internet users & 20 (users per 100) & 10 (users per 100 ) \\
\hline Absolute number of users & 2 & 2 \\
\hline Size of divide $(2: 2)$ & 2 & 2 \\
\hline \multicolumn{3}{|l|}{ Within-country income differences } \\
\hline Regional distribution & 2 urban users & 1 urban user 1 rural user \\
\hline Per capita income & $\$ 200$ & $\$ 100$ \\
\hline Distribution of income & $2 \times \$ 200$ & $\begin{array}{l}\$ 150, \$ 75 \text { (where the urban and rural } \\
\text { areas each comprise } 50 \% \text { of the } \\
\text { country as a whole) }\end{array}$ \\
\hline $\begin{array}{l}\text { The global distribution of Internet } \\
\text { users by income level (in } \\
\text { descending order) }\end{array}$ & $\begin{array}{l}\$ 200,200,125,75 \\
\quad(\text { st.dev. }=61.2)\end{array}$ & $\$ 200,200,125,75$ (st.dev. $=61.2)$ \\
\hline
\end{tabular}

country. Given the difference between Internet use per 100 citizens, weighting by population size eliminates the original divide; there are now 2 Internet users in each country.

The next step involves the differences in income between these users in the rich as well as the poor nation. For, although the weighting procedure gave us a more accurate global map of Internet use, it told us nothing about differences among users within each particular country. In the next section of Table 1, I thus allow for such differences. Users in the developed country are assumed to have the same level of income, but inequality appears in the poor country since the one individual enjoys an income of $\$ 125$ and the other has an income of $\$ 75$, below the country average (of $\$ 100$ ). This difference arises from the division of the poor country into equivalent sized urban and rural areas. ${ }^{2}$ As is typical of such countries, the urban resident has a higher income than the person who resides in the rural area. I arrive finally at an array of Internet users in the world, whose incomes in descending order are \$200, 200, 125 and 75.

Without any information on the poverty line, however, this distribution of Internet users by income level tells us nothing about whether or not the poor are benefiting. Assume then, for example, that persons with $\$ 50$ and below can be described as living in poverty. Assume further a new global distribution given by $\$ 200,200,150,50$ (st.dev. = 70.7), in terms of which inequality has become more pronounced (the convergence of the user with $\$ 150$ towards the incomes in the developed country is more than offset by the widening gap between the inhabitants in the developing country). At the same time, however the poorest person, who lives in absolute poverty, now benefits from Internet use (how much satisfaction that person actually derives is of course entirely another question). To avoid

${ }^{2}$ This assumption is made purely for arithmetical simplicity. In reality, rural areas are often larger than urban, measured by the number of inhabitants in each. 
confusion it is worth stressing that I have in total described three possible distributions of Internet use by income category. The first and most equal is where the individuals in each country have the same per capita income levels: i.e., 1) 200, 200, 100, 100 (st.dev. 57.7); where there is inequality in the developing country which takes the form: 2) 200, 200, 125, 75 (st.dev. = 61.2) and: 3) where it takes the form 200, 200, 150, 50 (st.dev. = 70.7). The final distribution does most to offset the equalizing effect of weighting on the size of the digital divide.

As with the other examples that have been provided in this section, however, the numbers here have been chosen arbitrarily and there is no a priori reason to think that they reflect reality in any way. Let us now, then, apply the framework described in Table 1 to the debate over changes in the digital divide over the years when Internet use began to increase in the developing countries, namely, 1998-2004. The main question is whether the new concept of the divide will increase or narrow the gap at the end of this period, as compared to the figure shown in Table 2.

\subsection{Change in Internet Use and the Size of the Digital Divide, 1998-2004}

As shown in Table 2, the digital divide did close over the relevant period. In particular, the size of (the relative as opposed to the absolute) gap decreased from 28.3 in 1998 to just 8 in 2004. Though this much-heralded finding is mostly about growth in Internet use from a negligible level in developing countries (the low-base problem), this is not the main point I wish to deal with below. It is rather about the direction of the influence exercised by weighting these figures by population size and considering the inequality of Internet use within, rather than between countries. Following the logic of Table 1, let us first deal with the former correction.

\subsection{Weighting Changes in the "Shrinking" Digital Divide}

It is of course perfectly possible for weighting by country size to offset, partly or fully, the closing digital divide shown in Table 2. This would be the case, for example, if the countries that exhibited the largest gain in Internet use over the period happened to be relatively populous and located in the developed regions of the world. In reality, however the influence of weighting may very well run in the opposite direction, of narrowing the digital divide as it is conventionally measured.

Consider, in this regard, Table 3, which displays the percentage change in Internet use between 1998 and 2004 for a number of country and income groupings as well as for China and India, the two largest countries in the world.

Table 2 The digital divide 1998-2004

\begin{tabular}{lcl}
\hline & $\begin{array}{l}\text { Internet users per 100 persons } \\
1998\end{array}$ & $\begin{array}{l}\text { Internet users per 100 persons } \\
2004\end{array}$ \\
\hline Developed countries & 17.0 & 53.8 \\
Developing countries & 0.6 & 6.7 \\
$\begin{array}{l}\text { Size of the digital divide (relative } \\
\text { terms) }\end{array}$ & 28.3 & 8 \\
\hline
\end{tabular}

Source: ITU (2006) 
Table 3 Growth in Internet use 1998-2004 (selected countries and regions)

\begin{tabular}{|c|c|c|c|}
\hline Region/country & $\begin{array}{l}1998 \text { (users per } \\
100)\end{array}$ & $\begin{array}{l}2004 \text { (users per } \\
100)\end{array}$ & $\begin{array}{l}\text { Average percentage growth } 1998- \\
2004\end{array}$ \\
\hline Latin America & 1.2 & 11.5 & 143 \\
\hline South Asia & 1.2 & 26.1 & 346 \\
\hline Sub-Saharan Africa & 0.23 & 2.0 & 128 \\
\hline Low-income countries & 0.09 & 2.43 & 433 \\
\hline $\begin{array}{l}\text { Low middle-income } \\
\text { countries }\end{array}$ & 0.40 & 7.4 & 292 \\
\hline Developed countries $^{\mathrm{a}}$ & 17.0 & 53.8 & 36 \\
\hline China & 0.17 & 7.25 & 694 \\
\hline India & 0.14 & 3.24 & 369 \\
\hline
\end{tabular}

Notes: ${ }^{a}$ Data taken from a different source, namely, ITU (2006)

Sources: ITU (2006); World Bank, ICT at-a-glance tables

Most tellingly, what the table reveals is that in China, constituting as it does some $20 \%$ of the global population, the annual average increase in Internet use is almost double that of India and markedly higher than any country or regional grouping. This fact alone would make the weighted measure of the digital divide smaller than the result one gets according to the conventional calculus (though, of course, some countries will exert an influence in the opposite direction). Indeed, whereas the unweighted measure of the divide is 8 to 1 (ITU 2006), the calculations I have made using the data contained in Table 4, show that the weighted version is as low as 1.8 to $1 .^{3}$ With some 137 million users, the table indicates that China alone constitutes more than $50 \%$ of all users in developing countries.

A similar story, one should note, emerges from the debate over the change in the global distribution of income (the counterpart of what I have referred to above as the global

Table 4 World internet usage and the weighted digital divide

\begin{tabular}{lc}
\hline Regions/countries & Internet users (2006) \\
\hline Africa & $33,334,800$ \\
Developing Asia & $261,368,065$ (China 137,000,000) \\
Developed Asia (Japan, Taiwan, Korea, Singapore) & $137,341,000$ \\
Europe & $314,792,225$ \\
North America & $233,188,086$ \\
Latin America/Caribbean & $96,386,009$ \\
Oceania/Australia & $18,439,541$ \\
\hline
\end{tabular}

Notes: Developed $=$ Developed Asia, Europe, North America and Oceania

Developing = Africa, Developing Asia, Latin America/Caribbean

Thus, the weighted digital divide is

703,760,852 (Developed Asia + Europe + North America + Oceania/391,088,874 (Africa, Developing Asia, Latin America) $=1.8$

Source: Internet World Statistics (2007)

\footnotetext{
${ }^{3}$ Note that I am not advocating the replacement of the unweighted version by the weighted alternative. The point is only that the latter is more suitable for one particular concept of the digital divide.
} 
distribution of Internet users by income level). In particular, a number of researchers have confirmed the finding that the variance of the population-weighted GDP per capita has decreased since 1987.

The main reason is, of course that China has been growing and converging to the rich at rapid rates after 1978. This means that the measures of convergence based on 'each country, one data point' can show divergence, but when we give 'each citizen, one data point' the picture changes radically. The key factor is that the average Chinese person (and therefore, about $1 / 4$ of the world population) has experienced substantial convergence of their personal income (Sala-i-Martin 2002, p. 8-9)

It is also because of the rapid growth in China, equal to no less than one-third of global economic growth, that poverty among the world's population has decreased so rapidly (as manifest for instance in a reduction of those living below $\$ 1$ a day from $17 \%$ of the world's population in 1970 to 6.7 by the end of the 1990s (Barro 2002). What the weighting of China (or weighting more generally) does not tell us, however, is the change in the distribution of income or Internet use within countries. As shown in Table 1, this information is also essential to calculating the global distribution of Internet users according to their income levels and it is to this that I now turn.

\subsection{Examining the Distribution of Internet Use Within Countries}

Ideally, I would want to know about changes in income inequality among Internet users over the same period, 1998-2004. Since such data are unavailable it is fortunate that I can infer the direction of change in certain developing countries from information about levels of Internet use. And as will shortly become apparent, this information all points in the same direction. Consider first the entries contained in Table 5, which contain descriptions about the income or geographical aspects of Internet use in a sample of developing countries (including China, the dominant influence in determining the weighted digital divide between rich and poor countries over the period in question). ${ }^{4}$

In at least some developing countries therefore, use of the Internet seems to be almost entirely an urban phenomenon and since the ratio of urban to rural income is invariably

Table 5 Inequality in Internet use within developing countries (selected cases)

\begin{tabular}{|c|c|}
\hline Country & Observation \\
\hline China & $\begin{array}{l}\text { 'The urban and rural gap of Internet use is astounding; merely } 0.3 \% \text { of all Internet users live in } \\
\text { the countryside, and the urban network dissemination ratio is } 740 \text { times that of rural areas' } \\
\text { (Wensheng 2001, p. 540). In the post } 1997 \text { period there was a 'dramatic and continuous' } \\
\text { increase in the ratio of urban to rural per capita income, from } 2.47 \text { to } 3.11 \text { in } 2002 \\
\text { (Chandresekhar and Ghosh 2006) }\end{array}$ \\
\hline Botswana & $\begin{array}{l}\text { From a household survey, Internet penetration stood at } 0 \% \text { for rural and } 4.55 \% \text { for major urban } \\
\quad \text { (Sebusang et al. } 2005, \text { p. } 43 \text { ) }\end{array}$ \\
\hline Namibia & $\begin{array}{l}\text { 'Of the } 51 \text { households that had at least one household member that uses the internet, } 72.5 \% \\
\text { lived in major urban, } 27.5 \% \text { in other urban and none in rural areas' (Stork 2005, p. 116) }\end{array}$ \\
\hline $\begin{array}{l}\text { South } \\
\text { Africa }\end{array}$ & $\begin{array}{l}\text { 'Of the respondents who have Internet connections at home, over } 80 \% \text { are in metropolitan } \\
\text { areas, } 20 \% \text { in other urban areas and none in rural areas' (Gillwald et al. 2005, p. 146) }\end{array}$ \\
\hline
\end{tabular}

\footnotetext{
${ }^{4}$ Note that the overall inequality in China over the recent past has sharply increased, partly, one would think, because of differences in Internet adoption among rich and poor members of that country.
} 
higher than one (sometimes much higher) in the Third World, this fact must mean that a highly unequal pattern of change in Internet use has occurred. While the extent of the rise in intra-developing country inequality is to gauge on the basis of available data, it will certainly have offset the role of China in narrowing the digital divide as it is conventionally measured and in principle could even have reversed that effect (For, I am not talking here about a gradual shift in inequality over a period of say 30 years, but rather a sudden spurt of inequality from a zero or negligible base).

More problematic, perhaps, than the rise in inequality in Internet use in recent years is the fact that this technology has barely impinged on rural areas of developing countries where the vast majority of the poor are concentrated. So even in the case where weighting offsets the rise in inequality within countries and the overall effect is a reduction in the size of the digital divide compared to the usual mode of calculation, the poor will not register as Internet users. Poverty in China has gone down dramatically but those that remain in this condition do not avail themselves of the benefits (potentially) afforded by the Internet. ${ }^{5}$

\section{Conclusions}

This note has advanced the case for a new concept of the digital divide, one which takes into account the different population size of developing countries as well as the way in which the income of Internet users varies within such countries. After presenting a detailed arithmetic example of what the transition from the original to the new concept actually entails, and what gains in information would be attained in the process, I then use the recent debate over the narrowing of the digital divide to illustrate the distinction between the two concepts. What emerges from this exercise is that when developing countries are weighted by population size, the exceptionally rapid recent growth of the Internet in China serves to narrow even further existing measures of the shrinking divide between rich and poor countries. Indeed, my preliminary results suggest that the ratio of Internet users in developed as against developing countries, is only 1.8. On the other hand, in China as elsewhere in the developing world, this recent growth has been accompanied by sharp increases in inequality among Internet users and a failure to reach the rural poor. Increasing within-country inequality of this kind offsets the effect of weighting developing countries by population size, though at this point there is no way of assessing whether the one effect is greater than the other.

Moving empirically towards the new concept of the digital divide can, as shown above, be most readily accomplished by taking a weighted measure of Internet use across developing countries. In fact, from the point of view of the new concept, this exercise alone would result in an improved measure as compared with the one that is commonly used. Finding data on the intra-country distribution of Internet users by income level in developing countries, on the other hand, is a far more difficult and expensive undertaking. Some household surveys (especially in Africa) have been conducted with the specific goal of eliciting such information, but in general only a limited number of countries collect data on ICT use at this level. A widespread change in this practice-in favour of routinely collecting data on income levels of users-would seem to be the least costly way of gathering the necessary cross-country evidence.

\footnotetext{
5 Nor, apparently, did the rural poor who have now moved above the poverty line, since the Internet is and was almost an entirely urban phenomenon.
} 


\section{References}

Barro, R. (2002). The UN is dead wrong on poverty and inequality. Business Week, 5 June, Issue 3781. Chandrasekhar, C., \& Ghosh, J. (2006). Rising inequality in China. The Hindu Business Line, January 3. Gillwald, A., Esselaar, S., Burton, P., Stavrou, A. (2005). South Africa. In A. Gillwald (Ed.), Towards an African e-index: ICT access and usage, South Africa: The LINK Centre, Wits University.

ITU (2006). World telecommunication/ICT development report, Geneva.

Sala-I-Martin, X. (2002). 'The disturbing 'rise' of global inequality', National Bureau of Economic Research, Working Paper 8904.

Sebusang, S., Masupe, S., Chumai, J. (2005). Botswana. In A. Gillwald (Ed.), Towards an African e-index: ICT access and usage. South Africa: LINK Centre, Wits University.

Stork, C. (2005). Namibia. In A. Gillwald (Ed.), Towards an African e-index: ICT access and usage. South Africa: LINK Centre, Wits University.

UNCTAD, (2006). The information economy report, Geneva.

Wengsheng, W. (2001). Bridging the digital divide inside China, Report of the Digital Opportunity Task Force, 2001. 